\title{
Retraction Note: Two genetic changes in cis-regulatory elements caused evolution of petal spot position in Clarkia
}

Peng Jiang (D) and Mark Rausher (iD

Retraction to: Nature Plants https://doi.org/10.1038/s41477-017-0085-6, published online 3 January 2018.

This Letter is being retracted because, in follow-up experiments, key aspects of the original results have not been able to be replicated. The accuracy of the $M y b 1$ and other sequencing information cannot be confirmed; the accuracy of the viral-induced gene silencing (VIGS) analysis, the identity of specimens in phenotype photographs and CPC gene sequencing and expression also cannot be confirmed; amplification of CPC, the supposed Myb1 regulator using the reported DNA and primers, cannot be repeated; and the reported 5' sequence immediately upstream of $M y b 1$ cannot be independently identified.

Mark Rausher agrees to the Retraction. We were unable to obtain a response from Peng Jiang.

Published online: 26 June 2020

https://doi.org/10.1038/s41477-020-0728-x

(c) The Author(s), under exclusive licence to Springer Nature Limited 2020 